\title{
AGENTES DE SAÚDE VOLUNTÁRIOS: UMA NOVA ESTRATÉGIA DE ATENDIMENTO À SAÚDE DA POPULAC̣ÃO NA PERIFERIA URBANA
}

Sônia Maria Soares*

\begin{abstract}
RESUMO - Este trabalho é sobre um estudo realizado com agentes de saúde, que foram treinados por instituições pertencentes a hospitais do INAMPS, para atuar como voluntários nas áreas metropolitanas periféricas da cidade do Rio de Janeiro. Utilizando o processo de urbanização e o problema de atendimento à saúde na periferia urbana relacionado à inferência do Estado como referencial teórico, o presente trabalho procura: - analisar, através da representação dos agentes de saúde sobre seu fazer cotidiano com o uso de uma sabedoria popular, os traços básicos do atendimento à comunidade; - analisar as implicações legais da inserção de um agente de saúde como um voluntário na periferia urbana. $O$ autor escolhe uma abordagem qualitativa que procura estudar esta realidade através do discurso do grupo estudado, da observação participante, das entrevistas e das análises dos relatórios elaborados pela comunidade.
\end{abstract}

ABSTRACT - This work is about a study performed with health agents that were trained by institutions pertainings to INAMPS hospitals, to act as volunteers in the metropolitan periphery areas of the city of Rio de Janeiro. Taking the urbanization process and the health attendance problem in the urban periphery related to the State's interference as the theoretical reference, the actual work seeks: - to analyse, through the health agents representation about their daily doings with the use of a popular wisdom, the basic features of the attendance to the community; - to analyse the legal implications in the insertion of a health agent as a volunteer in the urban periphyery. The author has chosen a qualitative approach that seeks to learn this reality throughout the speech of the studied group, the participant observation, the interviews and the analysis of the reports elaborated by the community.

\section{INTRODUC̣ÃO}

A década de 70 marca o surgimento da Medicina Comunitária e de propostas formuladas por agências internacionais como a Organização Mundial de Saúde, destinadas a garantir a extensão do cuidado à saúde a populações pobres urbanas e rurais (DONNANGELO, 1979). Dentre essas, deve ser ressaltado o movimento em prol da Assistência Primária de Saúde que busca racionalizar a produção e distribuição dos serviços de saúde, bem como reduzir as lacunas entre o estado de saúde dos países em desenvolvimento e desenvolvidos.

As estratégias para o cumprimento dessa proposta enfatizaram diversos aspectos, dentre eles a preparação de novas categorias de pessoal de saúde. $\mathrm{O}$ do- cumento elaborado após a Conferência de Alma-Ata (OMS, 1978) propõe a preparação de pessoas da comunidade, bem como a incorporação dos praticantes da medicina popular para prestar assistência de saúde na comunidade. Sabe-se entretanto que a prática da utilização de pessoal auxiliar, bem como voluntários nos serviços de saúde não se constitui uma novidade, uma vez que alguns países do Terceiro Mundo, como a Tanzãnia, Sudão, Índia e também países da América Latina como Venezuela, México, Costa Rica, vêm adotando esta experiência no âmbito do seus sistemas de saúde (OMS/UNICEF, 1979). Entretanto, vê-se que a utilização de pessoas da comunidade para assumir a prestação de assistência de saúde à população vem sendo questionada por diferentes profissionais de saúde, gerando até hoje grandes polêmicas.

* Professora Assistente $\mathrm{R}_{3}$ do Departamento de Enfermagem Básica da Escola de Enfermagem e Obstetrícia da Universidade Federal de Minas Gerais. 
As objeções levantadas prendem-se a aspectos sociais, econômicos e políticos, tais como a baixa qualificação do pessoal auxiliar, o descompromisso com a comunidade, o exercício ilegal da medicina, enfermagem e outras profissões e a característica das atividades que devem ser desenvolvidas. Esta problemática torna-se mais aguda quando se concretiza a sua condição de integrante do serviço de saúde como voluntário.

Com efeito, é importante entender como e porque este tipo de proposta que treina pessoas da comunidade para uma atuação voluntária junto aos serviços de saúde vem recebendo apoio de algumas instituições, ganhando espaço para sua implantação nas áreas da periferia urbana. Enfim, essa problemática é abordada a partir de um referencial teórico, que situa os serviços de saúde como bens de consumo coletivo, como direito do cidadão e dever do Estado dentro da perspectiva evolutiva do processo de urbanização.

Pretende-se, com este trabalho, contribuir para um posicionamento mais esclarecido da enfermagem frente à implantação de programas de saúde pautados no discurso e slogans da Assistência Primária de Saúde, bem como oferecer subsídios para discussão sobre a prática do agente de saúde na periferia urbana.

Para sua realização foram estabelecidos os seguintes objetivos:

- Caracterizar os agentes de saúde voluntários.

- Analisar os traços fundamentais da assistência de saúde prestada à comunidade a partir da representação de cada um sobre o seu fazer cotidiano.

- Analisar as implicações da inserção do agente de saúde voluntário na prestação de assistência de saúde em áreas da periferia urbana.

\section{REFERENCIAL TEÓRICO}

Para compreender as características e implicações da ação do agente de saúde voluntário, no atendimento de saúde à população em áreas da periferia, partiu-se das suas relações com a problemática da urbanização. As contradições inerentes ao avanço do modo de produção capitalista induzem um tipo de atendimento de saúde desigual e diferenciado. Percebe-se que essa discriminação e inadequação de oferta de serviços de saúde faz parte de uma lógica própria da urbanização, expressando descompasso entre a expansão da concentração de atividades industriais e a expansão da disponibilidade dos meios de consumo.

As limitações ao acesso aos bens de consumo coletivo nas zonas urbanas, insere-se num processo histórico, de forma que a importância atribuída à sua distribuição à população varia em função do desenvolvimento das forças produtivas e da capacidade de organização e luta das classes sociais (KOWARICK, 1979). Assim, o surgimento de contradições e seu agravamento com a expansão urbana pela concentração de grandes contingentes populacionais em periferias insere- se nas estratégias de sobrevivência dessa parcela da população. São categorias sociais atingidas pelo processo de mudança social, egressos pela transição de sociedades rurais e sociedades cujo avanço da industrialização acelera o processo de urbanização. Esse desenvolvimento criou, cada vez mais, novas necessidades para a reprodução da força de trabalho. Aumentou a demanda por serviços de infra-estrutura (água, esgoto, asfaltamento de ruas, iluminação privada e pública, etc.) e por um sistema de transportes coletivos mais rápido e eficiente (MOISÉS \& ALIER-MARTINEZ, 1981). A dotação de infra-estrutura urbana é legada à intervenção do Estado, cabendo-lhe a responsabilidade deste processo, segundo os mesmos autores. Entretanto a tomada de consciência do Estado da responsabilidade pelas condições reprodutivas, tem sido relegada a segundo plano, privilegiando a criação e ampliação das condições gerais de produção.

No caso do setor saúde, verifica-se esse tipo de problema, uma vez que a intervenção do Estado tem sido direcionada para o esforço do setor privado (OLIVEIRA \& TEIXEIRA, 1986).

A incapacidade do Estado de atender às necessidades de implantação de serviços que ofereçam condições para acolher os problemas básicos de saúde da população, assim como de outros bens de consumo coletivo, cria oportunidades para o surgimento, entre as classes populares, dos movimentos de reivindicação de serviços sociais urbanos (MOISÉS \& ALIER-MARTINEZ, 1981). Este tipo de organização faz emergir uma forma de conflito social diretamente ligada não mais à produção, mas à melhoria da qualidade de vida cotidiana. Observa-se, entretanto a partir desses movimentos uma intervenção do Estado apenas paliativa originando a partir da própria população formas alternativas para obtenção desses serviços. É então a partir desses aspectos, que se pretende discutir a problemática de inserção de agentes de saúde voluntários no atendimento aos problemas de saúde da população da periferia urbana.

\section{METODOLOGIA}

Optou-se pelo estudo de caso partindo das concepções da pesquisa participante (BRANDÃO, 1983).

\section{O Local da Pesquisa}

O trabalho foi realizado através do Setor de Saúde Comunitária de um hospital do INAMPS, localizado na zona norte da cidade do Rio de Janeiro. Estes setores foram criados nas unidades do INAMPS em meados da década de 70 e, na ocasião, foram previstas as seguintes atividades: educação sanitária individual e em grupos, imunização, controle de pacientes em tratamento tisiológico. Entretanto, os serviços expandiram suas ações criando outras frentes de trabalho. Este foi o caso 
do referido hospital, que tinha como filosofia de trabalho o treinamento de pessoas da comunidade, para atuarem como voluntários na prestação de serviços de saúde em áreas da Baixada Fluminense e também nas favelas localizadas nas imediações do hospital. Isto porque grande parte da clientela deste serviço é oriunda de localidades como Caxias, Nilópolis, Realengo, São João de Meriti, áreas desprovidas de uma rede de serviços de saúde.

\section{A Seleção dos Agentes de Saúde}

Fazem parte deste trabalho agentes de saúde que desenvolvem sua prática como voluntários. Para escolha desses informantes, adotou-se como estratégia o acampamento das reuniões de supervisão. Estas eram promovidas mensalmente pelos profissionais de saúde, coordenadores do projeto. 0 grupo participante era constituído de vinte a vinte e cinco agentes, que mantinham uma presença constante. Nestas reuniões, através de conversas informais, foi possível ir conhecendo os agentes, percebendo as dificuldades e as características do trabalho realizado na comunidade. Ao mesmo tempo, ia sendo colocado para o grupo a proposta de iniciar discussões mais ampliadas sobre o seu fazer cotidiano como agente de saúde. Diante do interesse manifestado pelos agentes, decidiu-se pela realização de uma reunião com todo o grupo, para esclarecimento da proposta. Dos 13 participantes desta reunião, muitos fizeram perguntas, deram sugestões, acharam a idéia promissora e demonstraram interesse em fazer parte do trabalho. Porém, desses 13 agentes, 2 ficaram impossibilitados de assumir compromisso com o grupo um por motivos de ordem pessoal e outro pela incompatibilidade do horário. Os demais declararam aceitação e disponibilidade e constituíram a amostra do presente estudo.

\section{Coleta de Dados}

A coleta de dados ocorreu no período de agosto de 84 a julho de 85 , e foi dividida em três etapas:

a. Entrevistas com os coordenadores do projeto.

Estas foram realizadas através de questões abertas, com a finalidade de conhecer os objetivos da proposta de treinamento dos agentes de saúde para uma atuação voluntária nas comunidades. Outro aspecto dessas entrevistas consistia em estabelecer um clima de cooperação para o desenvolvimento deste trabalho.

b. Análise dos relatórios de atividades mensais.

Os relatórios são instrumentos adotados pelo Setor de Saúde Comunitária com o objetivo de controlar os atendimentos realizados pelos agentes nas comunidades. Apesar das exigências do serviço quanto à sua entrega mensal, muitos não o fazem. Foram utilizados todos os relatórios disponíveis no Setor, no período de agosto a dezembro/84, perfazendo um total de 34 relatórios elaborados por 19 agentes de saúde. Para análise dos relatórios, adotou-se como classificação temá- tica: idade e sexo da clientela, queixas mais freqüentes, medicação distribuída e cuidados prestados.

c. Reuniões de discussão com o grupo de agentes de saúde.

Esta etapa desenvolveu-se em dez reuniões que foram gravadas em fitas cassete, mediante autorização dos participantes, totalizando 20 horas de gravação. 0 procedimento foi escolhido para facilitar a captação da espontaneidade dos depoimentos.

Os temas das reuniões foram colocados conforme roteiro (Anexo 1), elaborados após o primeiro encontro com os agentes, no sentido de introduzir questões sobre o seu fazer cotidiano na comunidade que permitissem aos participantes pensar e discutir problemas relativos à sua prática.

Através da utilização dessa modalidade de técnica, os dados descritivos foram transcritos e organizados obedecendo os seguintes tópicos:

- Caracterização dos agentes de saúde voluntários.

- Assistência de saúde prestada à comunidade.

- Implicações da inserção do agente de saúde voluntário na prestação de assistência de saúde à comunidade.

\section{ANÁLISE E INTERPRETAC̣ÃO DOS DADOS}

\section{Caracterização dos Agentes de Saúde Voluntários}

O grupo selecionado era constituído por doze mulheres e um homem. Eram senhoras com predominãncia de 44 a 64 anos, a maioria delas, mães com mais de dois filhos. Trajavam vestuário comum e, sobre este, jaleco branco e crachá de identificação com logotipo do INAMPS.

Quase todos residem em domicilio próprio com seus familiares. $\mathrm{O}$ local de residência eram três favelas da zona Norte da cidade do Rio de Janeiro (Marcílio Dias, Morro Guaíba e Morro da Penha) e distritos de Duque de Caxias, São João do Meriti e Santa Cruz, na região da Baixada Fluminense. A procedência dessas pessoas eram variável, sendo a maioria de origem nordestina.

Todas se dizem católicas, com exceção de uma, que se revelou espírita. Além das ocupações do trabalho doméstico, quatro são costureiras, duas cabeleireiras, duas professoras do MOBRAL, uma chuneleira, uma parteira e outra faxineira. Referem-se ainda ao desenvolvimento de trabalho voluntário na Associação de Moradores e na Pastoral da Igreja:

"Trabalho na associação de moradores e na catequese. Este ano tenho vontade de sê animadora de catequese. E também faço meu trabalho de agente de saúde". (D.S.O. - Campos Elíseos)

"Sou fundadora da Associação de Saracuruna... sempre trabalhei como faxineira, só que agora tô desempregada. Tô mal pra caramba! Sou catequista também na comunidade. Agora vou pegá um grupo de jovens de 15 a 20 anos". (M.C. Saracuruna) 
"Além de sê agente de saúde e trabalhá na comunidade, tenho vários trabalhos: trabalho com as vicentinas, que é um trabalho caridoso". (M.C.V. - Santa Cruz da Serra)

"Eu trabalhei 16 anos de costureira, depois eu parei de trabalhá, continuei ajudando. Fiquei cuidando de minha mãe". (F.C. - Brás de Pina)

A formação escolar limitava-se ao primeiro grau incompleto; uma das participantes declarou até que não sabia escrever nem ler, quando iniciou o trabalho na comunidade:

\section{"Senti até vontade de i pro colégio aprendê al- guma coisa a favor daquelas pessoa, do povo, da- quelas receita que eu recebia do pessoal. E meu filho até preguntá: 'ô mãe, como é que você aprendeu tanta coisa?' ". (M.C. - Saracuruna)}

A apresentação dos relatórios, quanto à sua escrita, demonstrou de certa forma a baixa escolaridade dos agentes, já que a grande maioria dos documentos apresentam erros de nível primário.

A renda familiar é avaliada sempre como insuficiente e não cobre os custos da reprodução.

"Tenho quatro filhos. Nenhum trabalha. Um é franciscano e o outro tem 15 anos. Eu botei no colégio pra estudá à noite pra vê se ele arruma um trabalho, porque eu não vou deixá ele à toa durante o dia, não dá. Rapazinho, é adolescente, sem trabalhá, não dá mesmo. Tem uma garota de 16 anos que trabalha em casa de familia. Ela vai e vem todo dia. Trabalha em duas casa. Com isso paga o colégio, que é $35 \mathrm{mil}$. Só dá mesmo prá o colégio, quase não ajuda em casa. Meu marido é aposentado. Ele é doente, aposentado, ganha uma 'mixaria', cento e sessenta e poucos mil cruzeiros (...) Hoje em dia eu fracassei, fracassei num ponto, sabe, eu financeiramente... meu marido adoeceu e aposentou, não teve mais cura pra trabalhar e nesse ponto eu fracassei... Aí eu tive que enfrentá uma casa de familia, uma coisa e outra..." (M.C. - Saracuruna).

"Tenho uma pensão de 500 mil cruzeiros e ainda pago aluguel. Meu filho trabalha, mas assim mesmo é pouco, fora luz e gás que a gente paga. (...) um dos meus filhos não pode trabalhá, porque é nervoso, mas não é maluco, recebe auxiliodoença do INPS, que não é grande coisa...' (E.P. - Penha)

Vê-se que as condições de vida que o grupo reúne são precárias, com subempregos, pensão do INPS. A renda familiar é tida como insuficiente, o que estimula a lançar mão de outras ocupações, no sentido de dilatar os rendimentos.

Os interesses em realizar o curso de agente de saúde são diversos. Mobilizados pela condição de vida, a motivação em conhecer as questões de saúde, permeiam também no âmbito desses interesses aspectos relacio- nados com os trabalhos da igreja e também a necessidade de um vínculo empregatício.

"Eu acho que sempre tive vocação pra essas coisa. Eu sempre gostei de fazê um curativo e vim tentando o curso e assim só depois de velha é que consegui". (G.V. - Codora)

Percebe-se por ora um ideal não concretizado de ser um médico ou enfermeira.

"É. Uma coisa que eu sempre tive vontade. Eu quando era pequena que estava na escola eu dizia: 'tenho fé em Deus que um dia ainda vou trabalha em hospital'. Tenho vontade de ser enfermeira, tenho fé em Deus. Eu tive oportunidade de hoje em dia ser uma grande dra. meu marido tinha, quando eu tive essa criança nas trompas no Getúlio Vargas..."' (A.V.F. - Brás de Pina)

O caráter de opção em ser agente de saúde voluntário prende-se também à necessidade de prestígio social e do status quo que o "saber" sobre a saúde conferindo-lhe uma posição hegemônica perante a comunidade.

" Olha, sempre tive vontade de fazê um curso desse, e vou servi muitas pessoa, mas primeiro eu quero sabê sobre saúde". (A.M. - Campos Elíseos)

Vê-se, portanto, que os agentes de saúde, sujeitos deste estudo, apresentam características diferentes se comparados com outros treinados em programas de Assistência Primária de Saúde da América Latina como Costa Rica, Guatemala, Venezuela (CAMAAERT, 1981). Nestes casos os agentes são incorporados como força de trabalho e não como ocupacionais inseridos paralelamente no sistema de prestação de serviços de saúde.

\section{Assistência de Saúde Prestada à Comunidade}

A inoperância dos serviços de saúde nas comunidades da Baixada Fluminense, bem como nas árvores faveladas foram queixas constantes dos depoimentos dos agentes de saúde:

"A casa de saúde lá de Caxias só é bom pra ganhá menino, só é o que é bom lá, porque o resto..." (D.S. - Campos Elíseos)

Esse quadro reforça uma assistência de saúde que fica a cargo de soluções alternativas implantadas muito mais por política e clientelística do que com o objetivo de suprir as necessidades mais imediatas da população. A sociedade ambulatorial é uma dessas alternativas que o agente de saúde descreve como forma de solucionar o problema do atendimento de saúde:

"É porque nós temos uma sociedade ambulatorial. Os moradores que têm conhecimento querem participar. Nós temos uma sociedadezinha que agora está suspensa, então eles pagam uma taxa que parece de mil cruzeiros e tem assistên- 
cia médica e dentária, exame de sangue e de fezes já paga um pouquinho mais". (M.C. - Saracuruna)

Além da questão alternativa que formaliza o atendimento à população de modo mais barato e certamente com menos problemas que as filas do INAMPS, o atendimento realizado enfrenta carência de recursos financeiros e técnicos.

“Essas seringas do hospital eu aplico e acaba rápido. (...) é material para a gente trabalhar que não tem". (M.C. - Saracuruna)

A falta de recursos para a realização do trabalho leva os agentes à mobilização em torno dessa questão e muitos conseguem obtê-los junto à Fundação Bradesco, Igreja e na própria comunidade.

Denota-se, a partir dos aspectos apontados pelos agentes de saúde, o papel que o Estado tem desempenhado no suprimento e administração dos serviços de saúde. Para SCHMIDT \& FARRET (1986), o Estado como gerente do capital social dá prioridade à criação e ampliação das condições gerais de produção, ficando os serviços de bens coletivos em lugar secundário, como é o caso dos serviços de saúde. A incapacidade do Estado de atender as necessidades de implantação de serviços que possibilitem a solução de problemas básicos de saúde cria oportunidades para a ampliação da assistência com base na prática do agente de saúde, prevalecendo mais o nível da atenção individualizada do que coletiva.

A assistência prestada à comunidade pelos agentes de saúde parece ser bem diversificada na medida em que não existem condutas homogêneas, ou seja, cada um faz de tudo um pouco, conforme sua convicção e experiências anteriores.

Revela-se, portanto, um estilo assistencial próprio, ora permeado por relações de troca legitimada pela caridade, ora por uma relação do poder conferida por um saber que os diferem das demais pessoas da comunidade. Constata-se, através dos relatórios elaborados mensalmente pelos agentes de saúde e também dos seus depoimentos, o tipo de clientela, as queixas mais freqüentes e os atendimentos realizados. A clientela atendida era bem diversificada, registrando-se um atendimento de $70 \%$ na faixa etária de $0-5$ anos. A maioria dos atendimentos são realizados de maneira informal e no próprio domicíiic. Limitavam-se a procedimentos de enfermagem tais como curativos, aplicação de injeções e verificação de pressão arterial:

“... o meu trabalho de Agente de Saúde é aplicá injeção, verificá pressão e batê um papo com as pessoa (...) também ensino pras pessoa as dieta, os chazinho". ( - Saracuruna)

“... sempre as pessoas me procurava pra eu dá injeção e fazê curativo..." (F.S.O. - Brás de Pina)

A.V.S., agente de saúde, relata sua experiência como parteira:
“Uma moça lá, vizinha minha, que o marido dela foi chamá a assistência, mas não deu tempo de chamá e eu fui fazê o parto, depois os médicos chegaram, a menininhajá tava de banho tomado."

Os casos de aborto eram freqüentes; porém, a Agente de Saúde afirma que prefere não indicar o que sabe, pois tem medo da questão legal.

" $O$ pessoal às vezes me procuram com esses probleminha, mas eu digo: - 'Olha, minha filha, se você tentou, voa pro hospital'..."

A capacidade de se identificar com os problemas das pessoas da comunidade permite aos agentes associar os atendimentos de saúde com atividades criativas ou de aconselhamento espiritual, o que de certa forma é colocado por muitos como recompensa individual:

“Eu vou na casa das pessoas desesperadas com dramas familiares e procuro orientá-las, acalmálas porque as pessoas estão tão desorientadas que nós precisamos entrá e ajudá, não só com um conforto, mas também um conforto espiritual" (E.P. - Penha)

Além da realização de campanhas de alimentação, vestuário, estas atividades implicavam no cuidado de doentes e até mesmo na resolução de problemas de ordem social:

“... e encontrava gente doente, eu não sabia passá remédio, nem nada, nem fazê nada, mandava eles fazê um remedinho caseiro como sempre, $e$ mando eles fazê até hoje... Levava pro ambulatório lá de Primavera, tocando a bicicleta com gente doente..." (M.C. - Saracuruna)

A assistência prestada à comunidade engloba ainda o fornecimento de medicamentos à população, mediante a apresentação de receita médica, o que na prática nem sempre se verificava:

“... eu pego a consulta e vejo se tem aquele remédio, então eu dou o remédio..." (C.F. - Parque Paulista)

" $O$ pessoal se acostumou a pegá remédio com a gente. Hoje mesmo foi uma lá pedi eritromicina e eu perguntei: você tem receita? Eu não... Não é mais assim, agora não pega mais remédio assim pra distribuir, como fazia antes". (D.S.C. Campos Elísoes)

O processo de medicalização é uma prática a quase todos os agentes. Os relatórios consultados evidenciam essa questão e parece a cada sintoma corresponder um medicamento de acordo com a lista padronizada pela CEME, que eles conhecem muito bem. A superutilização de medicamentos baseada na automedicação é prática corrente em nosso país, conforme demonstrou CORDEIRO (1980) em pesquisa realizada no município de Nova Iguaçu onde mais de 1/3 dos anti- 
bióticos foi tomado sem receita médica como também 2/3 das pílulas anticoncepcionais. Ele ressalta ainda que a própria medicina gera um processo de medicalização para resolver sintomas ligados ao comprometimento de condições gerais de vida, particularmente aquelas vinculadas à exploração da força de trabalho. Ficou comprovado no nosso estudo o uso indiscriminado de vermífugos e vitaminas, o que é compreensível diante das precárias condições de saneamento e alimentação das comunidades onde moram e atuam os agentes.

Em relação ao uso de vitaminas, CORDEIRO (1980) explica que o uso difundido destas "pode estar associado às precárias condições de alimentação e às representações difundidas pelo saber médico e por práticas ideológicas dominantes do valor das vitaminas para uma vida saudável'.

A distribuição de medicamentos é problemática quando não se tem orientação das indicações e efeitos colaterais do remédio, o que acaba por esbarrar num processo de limitação do saber do Agente de Saúde, além de ser uma atividade estritamente da competência médica. Observa-se que os medicamentos são obtidos através de ação clientelística e posteriormente fornecido à população.

' Também tinha um político lá onde a gente mora e a gente pedia, o que precisava e ele mandava remédio pra mim, mas agora não sei se vai mandar'. (A.M. - Campos Elíseos)

As orientações fazem parte da assistência prestada pelo Agente de Saúde e deve ser valorizada no contexto da sua prática. Isso porque elas exprimem a posição dos agentes perante os problemas de saúde que atingem mais diretamente a população.

"Eu acho a orientação em primeiro lugar, porque tem mães aí que não sabem nem como lidar com o próprio filho, nada. $E$ a orientação que eu falo é de que como essas mães agirem com seus próprios filhos, porque está demais". (E.P. - Penha)

As orientações fornecidas à população variavam ainda sobre educação sanitária, problemas alimentares, uso de medicamentos, amamentação, esquema de vacinação e até mesmo sobre problemas de aposentadoria. Este também parece ser o momento em que o agente de saúde esclarece a comunidade sobre o seu papel.

'Então a gente tem esse trabalho lá no posto de saúde. A gente dá esses cursinhos para as gestantes para elas terem mais cuidados na amamentação da criança, não dar muito mamadeira, ensinar as contrações..." (M.C. - Saracuruna)

O Clube de Mães oferece oportunidade para orientações em grupo, sendo debatidas questões sobre planejamento familiar, uso de anticonceptivos e cuidados de saúde:

‘ ... e também no Clube de Mães onde junta mais as mulheres a gente fala sobre a saúde como a mãe deve cuidá da criança, o lado sanitário". (D.S. - Campos Elíseos)

"Tem poucas mulheres casadas de pouco, que a gente também ameaça a orientar sobre planejamento familiar". (C.F. - Parque Paulista)

A prática do agente de saúde não ignora as formas de tratamento das doenças da comunidade através da incorporação de algumas práticas da medicina popular, tais como chás de ervas medicinais, simpatias e benzeduras.

' Ah, Dra. M.C., reza prá minha filhinha, que ela tá com o dedo quase caindo! E eu digo: isso aí não é com oração, não. Vamo lá no pé da bananeira. Cortava a folha da bananeira, espremia o sumo, o leite em cima da ferida, não deixava botá pó de café que meus pai diziam sempre que nunca colocasse pó de café, porque fazia muito mal que ressecava e depois quando o médico lavasse era uma tristeza, aquilo ficava agarrado. Então eu chegava lá, cortava a folha de bananeira botava aquele leite da bananeira é cica, então fechava". (M.C. - Saracuruna)

“Eu tenho orientado as pessoa prá tomá o chá de bananeira que é bom pra tosse e pneumonia. Minha irmã ela fazia só o chá e dava para a garota dela que tinha bronquite, melhorou, aí depois eu fui fazê o xarope. Fiz e dei para o meu primo, nunca mais teve. $O$ meu filho também eu curei, tratei de uma menina que ficava cansada tinha bronquite asmática e melhorou bem mesmo". (A.M. - Campos Elíseos)

Uma das agentes de saúde mostrou ao grupo como ela realiza simpatias no caso de crianças, que têm hérnias umbilicais.

'Entenda bem, quando a gente coloca o dedo assim, a gente sente aquele buraquinho aberto, se ele ainda tivé assim pra cima você enfaixa, bota o umbiguinho pra dentro, vai fazê assim, ele vai entrá, todinho, tem simpatias... tem a do vintém, aquele dinheiro antigo, você enrola numa gaze e coloca, você o enrola em uma gaze e coloca, você põe o umbigo todinho pra dentro e coloca e põe esparadrapo grudadinho, bem firme... tem a do dedal. Você tem que espetá o dedal no mamoeiro e conforme aquela carne do mamoeiro vai entrando no dedal, o umbigo da criança vai entrando também pra dentro. Uma criança também que tinha um 'ovinho' maior que o outro, sei lá, aquilo é hérnia, né, um carocinho grande aqui assim... Minha avó ensinou que garrasse um pedaço de morim e pedisse pra mãe dela pra cortá em cruz e que depois fosse no pé de pinhão, arriasse o couro ali e colocasse o pedaço de pano ali dentro, fechasse e amarrasse bem... Eu sei que o carocinho da criança sumiu". (A.V.F. - Marcílio Dias)

102 R. Bras. Enferm., Brasília, 41 (2): 97-106, abr./jun. 1988 
As práticas caseiras eram reforçadas por um ou outro agente de saúde, em virtude da falta de medicamentos e também dos ef eitos adversos que estes podem causar:
"Quando tem o remédio, a gente dá, quando não tem... eu ensino os chás, o xarope de balieiro pra substituí o iodeto de potássio, que eu levava da- qui, deu certo, todo mundo tá utilizando". (D.S.O. - Campos Elíseos)
“... é muito mais válido comprar a erva medici- nal do que usar esses remédios quimioterapêu- ticos que são piores do que ervas do mato". (J.L. - São João de Meriti)

A prática do espirtismo e orações é também alternativa encontrada para resolução dos problemas de saúde.

“... eu sou espírita e dou minhas consultazinhas, atendo a pessoas doentes, crianças, faço rezas" (A.V.F. - Marcílio Dias)

“... também fazia oração pras pessoas e eu faço até hoje, que chegavam e diziam que precisavam de uma orientação pra curá uma ferida e não do remédio". (M.C. - Saracuruna)

A assistência de saúde prestada à comunidade pelo agente de saúde com a incorporação das práticas da medicina popular reforça as conclusões de LOYOLA (1984), que destaca o desenvolvimento dessas práticas não como um fenômeno limitado apenas às regiões rurais, mas também como extensamente praticado no meio urbano. Essa mesma autora mostra ainda que a medicina popular tende a se desenvolver com mais força junto às camadas de renda mais baixa, ao contrário da medicina oficial, por possuir uma linguagem mais próxima das representações dessas camadas, além de se constituir uma alternativa mais econômica.

Enfim com base nos aspectos apresentados, verifica-se que assistência prestada à comunidade pelos agentes de saúde acontece em meio a improvisão aliada à falta de recursos técnicos e financeiros. Constatase por ora, que não existe um registro sistemático dos atendimentos realizados uma vez que os relatórios não são elaborados com freqüência e nem todos os agentes os fazem. Não existe estatística, prontuário, ou mesmo um controle do retorno dos pacientes, o que dificulta a avaliação da eficácia do se'ı trabalho enquanto agente de saúde. Mesmo as visitas domiciliares não são registradas.

Isso demonstra que o tipo de assistência prestada à comunidade delineia-se como informal, simbólica $\mathrm{e}$ marginal, desvinculada dos demais serviços de saúde da localidade e de baixa capacidade resolutiva. Enfim, trata-se de uma prática assistencialista e discriminatória considerada como paliativa das reivindirações populares frente à inoperãncia dos serviços de saúde oficiais na periferia urbana.
Implicação da Inserção de Agentes de Saúde Voluntários na Prestação de Assistência de Saúde

A prática voluntária realizada pelo agente de saúde, é estabelecida pelos profissionais de saúde como condição indispensável para o seu treinamento. Por ora é esclarecida essa condição, como ressalta um dos agentes de saúde:

"Eu acho o seguinte, quando nós fizemos este curso, nós já tivemos essa explicação que era voluntário, e não era com a finalidade de tê emprego de tê dinheiro, de tê nada nós íamos só aprendê alguma coisa pra nós é pra gente servi, a nossa comunidade, entãotodo mundo aceitou". (J.M. - Jardim Primavera)

Para essa mesma agente, o trabalho voluntário é visto como uma alternativa da comunidade, já que o Estado não assume investimentos com serviços de saúde, o que ela traduz como falta de condições de "pagá outras pessoas".

"Agora, como eles não têm condição de pagá outras pessoa e tem os Agente, e quem se prontifica em ajudá..." (J.M. - Jardim Primavera)

Essa questão suscita, entre os agentes de saúde, muitas discussões e reivindicações de remuneração pelo trabalho realizado como reafirma o depoimento abaixo:

"O pessoal se locomove de um local para outro
pra atendê a uma pessoa o que seria obrigação
do INAMPS, do Estado, e eles não fazem, a gen-
te é que vai atendê as pessoas, gasta dinheiro e
tem despesa, seria justo que o Estado desse uma
manutenção para o pessoal". (J.L. - São João de
Meriti)

Aos poucos as necessidades de sobrevivência sobrepõem-se ao idealismo do voluntariado e aparecem, além das reivindicações de remuneração, as de vínculo empregatício:

“... teve gente até que tava fazendo lá na comunidade, já tirando pressão, fazendo isso e aquilo, fazendo aquele alarde todo e depois tiveram a capacidade de i lá pro Dr. ... pedi emprego. Então ele falô bem claro que ele não tava lá pra dá emprego pra agente de saúde e que emprego no INPS era através de inscrição de concurso, que ele não podia chegá assim e dá um emprego, só porque eu tô trabalhando na comunidade e que agente de saúde era uma coisa pra voluntário e pra isso era pra comunidade, pra ele aprendê pra ele e ajudá na comunidade dele, sem nenhum compromisso. Agora eu acho válido, por exemplo, se depois eu tenho uma certa capacidade e se, por exemplo, como aqui já teve inscrição pra isso, inscrição pra aquilo, se eu vou fazê minha inscrição, lógico que pra mim é bom eu conseguir um emprego através desse conhecimento que eu já tenho"'. (D.S.O. - Campos Elíseos) 
Aparecem também situações da realização de estágios voluntários, como agentes de saúde em instituições hospitalares, o que de certa forma demonstra maior facilidade de incorporação futura nos serviços.

"Faço um estágio no SASE, pra aprendê um pouco mais e ganhá prática" (G.V. - Codora)

A discussão sobre a realização de um trabalho sem fins lucrativos fez com que aparecessem denúncias de agentes de saúde que vêm atuando na comunidade, transformando a prática do voluntariado em uma prática mercantilista.

"Em Caxias tem uma Agente de Saúde, M.A., que ela atende a comunidade. Se é aplicá injeções ou fazê um curativo, ela cobra, ela não faz de graça”.' (I.S.O. - Santa Cruz da Serra)

Diante dessa situação no próprio grupo, uma das agentes de saúde declarou que ela também mantinha essa mesma conduta.

"Mas é claro, injeção também eu cobro. Já é um trocado que entra" (E.S. - Penha).

Apesar de ser criticada pelo grupo, ela manteve sua opinião, mostrando que o trabalho deve ser voluntário apenas na comunidade; para outras pessoas, devese estabelecer um preço pelos serviços prestados.

"Nosso serviço é voluntário é dentro da comunidade". (E.P. - Penha)

"Mas é dentro da comunidade é que ela cobra". (I.S.O. - Santa Cruz da Serra)

“Ah! Na comunidade não, só a particulares... se é pobre, tudo bem, mas se pode ir na farmácia, então paga a mim, mas eu não vou como Agente de Saúde Comunitária". (E.P. - Penha)

Apesar da prática do voluntariado ser uma questão ideologicamente colocada desde o treinamento do grupo, vê-se que esta condição tem sido questionada por alguns agentes de saúde. É importante assinalar que alguns já percebem que estão sendo explorados ao assumirem $o$ atendimento de problemas de saúde da comunidade e mencionam que a responsabilidade é do Estado. Neste sentido propõem que os agentes de saúde se organizem para reivindicar seus direitos e também melhoria dos serviços de saúde.

Este depoimento reverte a necessidade de organização do grupo no sentido de verem concretizados seus anseios, principalmente para aqueles que já demonstram um nível de consciência maior com relação à sua prática. Para o agente de São João de Meriti, é muito clara a posição que o governo adota ao tratar dos problemas de saúde da população. Ele mostra que é obrigação do Estado investir em saúde e, portanto, conclama os Agentes de Saúde a se organizarem para reivindicar seus direitos, através de ações coletivas:

"É importante o Agente se unir. Acho que uma andorinha só não faz verão, mas se todos se uni e lutá pelos seus direitos, vai consegui alguma coi- sa melhor, vai consegui que o Governo dê um abono melhor para as pessoas, porque são pessoas que dedicam um tempo de sua vida em ajudá outras vidas e que não ganham nada pra isso. Muito pelo contrário, gastam do seu dinheiro e não é obrigação dele, é obrigação do Governo fazê (...) Então nós temo que nos uni. Se nós nos unirmo e lutarmo por algo melhor, nós vamos consegui algo melhor (...) é preciso que a gente se una e faça uma guerrinha com o Estado para ver se ele libera alguma coisa pra gente (...) Porque todos junto é melhor que dois ou três. É importante, porque a união faz a força, e nós unidos vamos nos torná um grupo forte e vamos conseguir nossos objetivos, que é melhorar nossas condições de trabalho. Mesmo que a gente não ganhe pelo trabalho que faça, mas que tenha pelo menos uma compensação (...) O INAMPS é obrigado a ceder o material, médico, recursos humanos pra fazê esse trabalho e eles não fazem; se a população não pressionar; eles não fazem nunca". (J.L. - São João de Meriti)

Além das implicações produzidas a partir de sua condição como voluntário, alguns agentes têm consciência que exercem uma prática que não é legitimada institucionalmente. Essa questão foi muito debatida no grupo, principalmente no que se refere a insegurança, que é gerada a partir dessa situação, expondo riscos à população que dela se utiliza.

"A dificuldade que eu tenho é o medo de desenvolver um trabalho de saúde eu e umas 3 ou 4 (...) uma coisa eu tenho que falar é que eu tenho medo de aplicar injeção, porque não sendo lugar certo... E se acontecer de eu fazer uma coisa assim qualquer, eu acho que dar um remédio, que eu ache que esteja certa que daquilo vai... a gente sente. Eu sei que tenho essa deficiência de dar o tratamento como agente de saúde, assim como eu posso dar e a pessoa ter uma alegria". (F.C. - Brás de Pina)

"Bem, a gente pega um machucado de uma pessoa, começa a fazer o curativo, depois ela vai para a casa de saúde aí 'quem faz esse curativo?' Pode estar bem feito ou pode não estar. Se não estiver daí vão dizer 'como é que vocês vão procurar um curioso para fazer isso, para fazer aquilo?' E a gente fica até mal visto". (J.M. - Jardim Primavera)

Não existiam documentos, leis que provassem a legitimidade do trabalho realizado pelo agente. A instituição que realiza o treinamento procura conferir legitimidade a essa prática, dando-lhe um certificado e um crachá, que não outorgam direitos para o exercício das atividādes enquanto voluntários. Entretanto, para alguns, a representação formalizada em relação à sua indumentária, é tão expressiva que para os lei- 
gos isto simboliza o poder, a autoridade em saúde da comunidade.

“ $E$ eu sei que é, porque às vezes você pode pensá que não significa nada, mas realmente você com o seu jaleco e com o seu crachá pelo menos pra aqueles que não entendem nada, olha assim, é uma autoridade." (J.M. - Jardim Primavera)

Para outra agente de saúde o crachá e o jaleco não deixam de conferir um certo status, inclusive caracterizando seu maior potencial em tomar certas providências.

"Então, eu acho que com um crachá, é claro, que eu não vou entrá no ônibus de jaleco e crachá toda hora, mas o crachá eu não largo, ele está na bolsa. Agora, se deixar o encaminhamento, $o$ jaleco e o crachá em casa você não pode agir".

Esta posição não é reafirmada por outros agentes que têm uma visão diferenciada quanto a vestimenta e refere-se ao "documentozinho" que ela gostaria de ter para se colocar como agente de saúde diante de situações como esta:

"Eu acho que a gente deveria tê... A gente tem esse crachá, mas não sei o que vale isso na hora". (D.S.O. - Campos Elíseos)

Outro problema que ainda não foi resolvido no nosso país, e que permeia a prática do agente de saúde, é sobre a prescrição de medicamentos por pessoas não legitimadas pelos serviços.

"O maior problema que eu vejo é porque eu recebo muito medicamento e tem certo medicamento que a gente não pode passá pro povo". (C.F. - Parque Paulista)

Partindo dos aspectos apresentados, vê-se que as implicações da inserção do agente de saúde voluntário, na prestação de assistência à comunidade, está relacionada à falta de integração desse agente com a rede de serviços oficiais de saúde e também a uma indefinição do seu papel no sistema de saúde.

\section{CONCLUSÕES}

A experiência deste trabalho leva-nos a concluir que o treinamento e a inserção de pessoas da comunidade, agentes de saúde, voluntários para a prestação de assistência de saúde em áreas da periferia urbana, consiste em uma nova estratégia que as instituições do governo vêm lançando diante da insuficiência de investimentos públicos no setor saúde. Delineia-se como alternativa a partir do momento que o Estado está ten- tando desvencilhar-se de uma tarefa por ele assumida no processo urbanização/industrialização lançando sobre os ombros da população a tarefa de organizar por sua própria conta e risco seu serviço de saúde. Verifica-se que o ingresso dos agentes como voluntários ocorre por motivações diversas que variam desde a necessidade de obtenção de emprego até a questão do prestígio social na comunidade, não prevalecendo o compromisso social com a comunidade. A assistência prestada à comunidade revela-se como assistencialista, com os agentes de saúde dissociados de outras lideranças da comunidade, desenvolvendo atividades segundo seu próprio juízo.

A questão do voluntariado, aliada à falta de legitimidade para o exercício da prática, foram os aspectos mais problemáticos enfrentados pelo agente de saúde.

Finalizando pode-se dizer que a prática do agente de saúde voluntário na periferia urbana reflete as contradições do nosso sistema de saúde, criando e reforçando níveis de assistência à saúde diferenciados para a população.

\section{REFERÊNCIAS BIBLIOGRÁFICAS}

1 BRANDÃO, C. Rodrigues. Pesquisa participante. 3. ed. São Paulo, Brasiliense, 1983.

2 CAMMAERT, M. Salud para todos en el año 2000 y el papel del auxiliar de salud. Boletin Pasccap. OPS/OMS, jun. 1981. (Programa de Adiestramiento en Salud Comunitaria de Centroamérica y Panamá).

3 CORDEIRO, H. A indústria da saúde no Brasil. Rio de Janeiro, Graal, 1980.

4 DONNANGELO, M. C. F. \& PEREIRA, L. Saúde e sociedade. São Paulo, Duas Cidades, 1979.

5 KOWARICK, L. A espoliação urbana. 2. ed. Rio de Janeiro, Paz e Terra, 1979.

6 LOYOLA, M. A. Médicos e curandeiros. Conflito social e saúde. São Paulo, Dif el, 1984.

7 MOISÉS, J. A. O estado, as contradições urbanas e os movimentos sociais. In: MOISÉS, J. A. et alii. Contradições urbanas e movimentos sociais. 2. ed. Rio de Janeiro, Paz e Terra, 1981.

8 MOISÉS, J. A. \& ALIER-MARTINEZ, V. Capitalismo e contradições urbanas. In: MOISÉS, J. A. et alii. Contradições urbanas e movimentos sociais. 2. ed. Rio de Janeiro, Paz e Terra, 1981 .

9 OLIVEIRA, J. A. A. \& TEIXEIRA, S. M. F. (IM) Previdência Social - 60 Anos de História da Previdência Social no Brasil. Petrópolis, Vozes, 1986.

10 ORGANIZAÇÃO MUNDIAL DE SAÚDE. Informe da Conferência Internacional sobre Atenção Primária de Saúde. AlmaAta, Genebra, 1978.

11 ORGANIZAÇÃO MUNDIAL DE SAÚDE/UNICEF. Proposições alternativas para $o$ atendimento das necessidades básicas de saúde em País em desenvolvimento, 1979.

12 SCHMIDT \& FARRET, R. A questão urbana. Rio de Janeiro, Zahar, 1986. 


\section{ANEXO 1}

\section{Roteiro das Reuniões de Discussão com os Agentes de Saúde}

\begin{tabular}{|c|c|c|}
\hline Data & Freqüência & Temário \\
\hline 07.02 & 14 & $\begin{array}{l}\text { Construindo uma proposta de trabalho } \\
\text { com os agentes de saúde. }\end{array}$ \\
\hline 26.02 & 12 & $\begin{array}{l}\text { Conhecendo o grupo e suas expectativas. } \\
\text { Um pouco da história de cada um... }\end{array}$ \\
\hline 05.03 & 10 & $\begin{array}{l}\text { A idéia de ser gente de saúde. Como tu- } \\
\text { do começou... }\end{array}$ \\
\hline 12.03 & 7 & $\begin{array}{l}\text { "Sempre a gente trabalha, sempre trata } \\
\text { a quem precisa". }\end{array}$ \\
\hline 19.03 & 9 & $\begin{array}{l}\text { Como o agente de saúde orienta a } \\
\text { comunidade. }\end{array}$ \\
\hline 26.03 & 8 & $\begin{array}{l}\text { Elaboração de uma proposta de orienta- } \\
\text { ção para o grupo de mães ou jovens da } \\
\text { comunidade. }\end{array}$ \\
\hline 02.04 & 8 & $\begin{array}{l}\text { "Lá na comunidade quase não tem re- } \\
\text { curso..." }\end{array}$ \\
\hline 09.04 & 10 & $\begin{array}{l}\text { Os agentes de saúde falam das dificulda- } \\
\text { des encontradas para o desenvolvimen- } \\
\text { to do trabalho na comunidade. }\end{array}$ \\
\hline 23.04 & 10 & $\begin{array}{l}\text { O agente de saúde discute sobre o apoio } \\
\text { recebido da igreja, associação de mora- } \\
\text { dores e do setor de Saúde Comunitário } \\
\text { do hospital. }\end{array}$ \\
\hline 08.05 & 7 & Avaliando o trabalho com o grupo. \\
\hline
\end{tabular}

